\title{
LIDERANÇA AUTÊNTICA E GESTÃo DO CONHECIMENTO
}

\author{
Fabiana Besen SANTOS ${ }^{1}$ \\ Edivandro TECCHIO \\ Francisco Antônio Pereira FIALHO ${ }^{3}$
}

\begin{abstract}
${ }^{1}$ Doutoranda do Programa de Engenharia e Gestão do Conhecimento - UFSC. fabibesen@ gmail.com
${ }^{2}$ Doutorando do Programa de Engenharia e Gestão do Conhecimento - UFSC. edivandro@gmail.com

${ }^{3}$ Doutor, professor no Programa de Engenharia e Gestão do Conhecimento - UFSC. fialho@egc.ufsc.br
\end{abstract}

\section{Recebido em: 24/05/2014 - Aprovado em: 30/06/2014 - Disponibilizado em: 30/07/2014}

Resumo: A liderança tem um papel importante na criação de valor, inovação e na articulação de estratégias de implantação da gestão do conhecimento. No âmbito da liderança existe uma discussão acerca da ética e autenticidade, principalmente, após os escândalos protagonizados por altos dirigentes de algumas organizações, em especial, nos Estados Unidos. Neste contexto, o objetivo deste artigo é contextualizar a teoria da liderança autêntica, amparada nos pressupostos da autenticidade e por fortes valores éticos/morais. É uma conduta interessante para as organizações intensivas em conhecimento visto que se preocupa em criar um ambiente organizacional positivo e com foco no desempenho verdadeiro e sustentável. A ética e autenticidade nas relações podem favorecer a criação e compartilhamento do conhecimento. Existem muitas possibilidades para estudos futuros (empíricos) que analisem a liderança autêntica e o seu desenvolvimento no ambiente social e organizacional.

Palavras-chave: liderança; liderança autêntica; autenticidade; conhecimento; gestão do conhecimento

\section{AUTHENTIC LEADERSHIP AND KNOWLEDGE MANAGEMENT}

Summary: Leadership plays an important role in value creation, innovation and articulation of strategies for implementing knowledge management. Under the leadership there is a discussion of ethics and authenticity, especially after the scandals perpetrated by senior leaders of some organizations, especially the United States. In this context, the aim of this article is to contextualize the theory of authentic leadership, based on the assumptions of authenticity and a strong moral/ ethical values. It's an interesting conduit for knowledge intensive organizations since cares to create a positive and focused on real and sustainable organizational performance environment. The ethics and authenticity in relationships can encourage the creation and sharing of knowledge. There are many possibilities for future studies (empirical) to examine the authentic leadership and its development in the social and organizational environment.

Keywords: leadership; authentic leadership; authenticity; knowledge; knowledge management

\section{Introdução}

A sociedade vivencia um período

de transformação, que se caracteriza por um processo de reorganização e reformulação de sua visão de mundo, dos seus valores básicos e de suas estruturas sociais e políticas (CASTELLS, 1999). As atividades que ocupavam o lugar central nas organizações deixam de ser aquelas que visam produzir ou distribuir objetos e passam a ser aquelas que produzem e distribuem informação e conhecimento (DRUCKER, 1993).

A liderança, neste contexto, passa a afetar o ambiente de trabalho na forma como ocorre à cooperação entre os indivíduos, no intercâmbio de conhecimentos, na delegação de responsabilidades e competências intra e interorganizacionais, em suma exerce influência em toda a dinâmica rede da aprendizagem, bem como no 
compartilhamento do conhecimento organizacional (BARTLETT; GHOSHAL, 2002). Os desafios iniciais da liderança direcionam a dois aspectos chaves: primeiro; o de acolher o novo paradigma emergente; e em segundo, o de conduzir o processo de mudança organizacional rumo à nova sociedade do conhecimento, a partir da criação de visão e valor, inovação e assunção de riscos necessários (KAPLAN; NORTON, 2004).

Nesse sentido, a liderança começa a ganhar força no contexto da gestão do conhecimento, com estudos realizados por diversos autores (HOLSAPPLE; JOSHI, 2004; PLESSIS; BOON, 2004; SUN, 2010; SOUSA). Porém, as diversas faces que envolvem o tema liderança, muitas vezes tornam difícil seu entendimento e seus benefícios. A liderança enquanto objeto de estudo compõe um quadro complexo e multidimensional.

A revisão dos estudos acadêmicos demonstra que existe uma grande variedade de abordagens teóricas para explicar as complexidades do processo de liderança. Observa-se que, ao logo do tempo, diversas abordagens sobre o tema surgiram. A análise da literatura (NORTHOUSE， 2004; YUKL， 2008) remete a diversas teorias de liderança, podendo-se citar: as abordagens tradicionais e as novas teorias da liderança, como: abordagem transformacional, abordagem da liderança autêntica, abordagem da teoria da liderança ética e abordagem espiritual. $\mathrm{O}$ foco desse estudo é a teoria da liderança autêntica.

A teoria da liderança autêntica é uma abordagem recente (GARDNER et al., 2005). Permeia uma gama variável de estudos e abordagens, porém em linhas gerais todas elas sugerem que a autenticidade tem como ponto inicial os próprios líderes por meio de sua autoconsciência, auto-aceitação, autoconhecimento, fé, ações e relacionamentos, passando pela promoção de relações autênticas com seus seguidores e associados, suportadas pela transparência, confiança, integridade e altos padrões morais (AVOLIO; GARDNER, 2005).

Portanto, contextualizar a liderança autêntica e expor apontamentos sobre sua importância para a gestão do conhecimento, constitui-se no objetivo deste artigo. Para alcançar esse objetivo, efetuou-se uma pesquisa na base de dados Scopus para encontrar artigos relacionados ao tema e material bibliográfico que fornece sustentação a discussão a seguir.

\section{Liderança autêntica}

O conceito de liderança autêntica é uma construção recente. Tem origem nos trabalhos de Kernis (2003) que colocou a autenticidade como fundamental para a 
autoestima (AVOLIO; GARDNER, 2005).

Surgiu do cruzamento de vários aspectos da liderança, de questões éticas e do comportamento organizacional positivo (WALUMBWA et al, 2008). Os proponentes da liderança autêntica apontam para o desejo de treinar e desenvolver líderes que pró-ativamente fomentam ambientes positivos e realizam negócios de forma ética e socialmente responsável (AVOLIO; GARDNER, 2005; AVOLIO; GARDNER; WALUMBWA; AVOLIO; LUTHANS; WALUMBWA, 2004; GARDNER; AVOLIO; LUTHANS; MAY; WALUMBWA, 2005).

As teorias sobre liderança autêntica permeiam uma gama variável de estudos e abordagens, porém, em linhas gerais sugerem que a autenticidade é estimulada pelos próprios líderes por meio da autoconsciência, autoaceitação, autoconhecimento, ações e relacionamentos. Por consequência, têm-se relações autênticas, suportadas pela transparência, confiança, integridade e altos padrões morais (AVOLIO; GARDNER, 2005).

Os elementos da autenticidade são relevantes ante as oscilações e desafios no cenário mundial que sugerem uma busca constante por um enfoque renovado. É necessária genuína liderança apta a restabelecer a confiança, a esperança e o otimismo frente a situações críticas e desafiadoras, ajudar as pessoas em sua procura por significado com base na autenticidade (AVOLIO; GARDNER, 2005).

Inicialmente, a liderança autêntica foi definida como um processo que promove as capacidades psicológicas positivas e um contexto organizacional altamente desenvolvido, resultando em uma maior autoconsciência, auto-regulação e comportamentos positivos por parte dos dirigentes e associados (LUTHANS; AVOLIO, 2003 apud AVOLIO; GARDNER, 2005). Mais recentemente, Walumbwa et al. (2008) conceituaram como um padrão de comportamento do líder que apoia e promove capacidades psicológicas positivas e um clima ético positivo, para promover uma maior autoconsciência, uma perspectiva moral internalizada, processamento equilibrado de informação e transparência relacional no ambiente de trabalho.

Essa forma de liderança está fundamentada na compreensão e interpretação dos processos de avaliação observados ou experimentados, bem como, na ética nos processos de decisão. Como ponto de partida, isto implica a adequação do foco sobre as percepções do indivíduo em um papel de liderança e como o indivíduo constrói o seu papel e meio ambiente (BEGLEY, 2006). É importante salientar que a liderança autêntica se 
estende para além da autenticidade do líder, abrangendo as relações autênticas com seus seguidores e demais stakeholders. Essas relações são caracterizadas por: orientação, transparência, abertura e confiança; voltada para objetivos dignos; e ênfase no desenvolvimento dos seguidores (GARDNER et al, 2004).

Não obstante, a conceituação de liderança autêntica, a exemplo do que ocorre com o conceito de liderança, não é consensual. Existem diversas definiçõos, mas, em geral, todos enfatizam a importância da coerência entre as palavras, ações e valores do líder (YUKL, 2008). Há um consenso no que se refere a quatro fatores componentes da liderança autêntica: processamento equilibrado; perspectiva moral internalizada; transparência nas relações e autoconhecimento.

O processamento equilibrado refere-se à análise objetiva dos dados relevantes antes de tomar uma decisão. A perspectiva moral internalizada diz respeito aos padrões morais internos que guiam uma pessoa e que é usado para autorregular seu comportamento. Já a transparência relacional está ligada à demonstração de autenticidade por meio do compartilhamento de informações e sentimentos apropriados a cada situação, ou seja, evitando mostrar emoções inadequadas. A autoconsciência refere-se à compreensão de suas forças, fraquezas, e a maneira como constrói o sentido de mundo. (AVOLIO; WALUMBWA; WEBER, 2009).

\section{Gestão do conhecimento}

A importância do conhecimento para a economia mundial é inegável (DRUCKER, 1993; OCDE, 1997). No entanto, o entendimento do que é conhecimento apresenta variações na literatura. Uma definição clássica, proposta por Platão aponta que conhecimento é uma crença verdadeira e justificada. Nonaka e Takeuchi (1997) seguem essa linha de pensamento e apontam o conhecimento como um processo humano dinâmico de justificar a crença pessoal com relação à verdade.

Definições mais recentes afirmam que o conhecimento pode ser entendido como uma combinação organizada de dados, assimilados como um conjunto de regras, procedimentos e operações aprendidos por meio da experiência e da prática (BHATT, 2001). É mais rico que a informação, com mais significado e é uma forma das organizações produzirem riquezas (SVEIBY, 2005).

Percebe-se que o conhecimento tornou-se $\mathrm{o}$ fator de produção mais importante para a nova sociedade que se consolida, a "sociedade do conhecimento". 
Esse entendimento torna imprescindível que o conhecimento seja gerenciado. O conceito de gestão do conhecimento está longe de ser um consenso. Não existe um conceito geral unanimemente compartilhado. Existem diversas definições para o termo gestão do conhecimento, conforme quadro $1^{1}$.

\begin{tabular}{|c|c|}
\hline Conceito & Autor \\
\hline $\begin{array}{l}\text { A capacidade de uma } \\
\text { organização de criar novo } \\
\text { conhecimento, disseminá-lo na } \\
\text { organização e incorporá-lo em } \\
\text { seus produtos, serviços e } \\
\text { sistemas. }\end{array}$ & $\begin{array}{c}\text { Nonaka e } \\
\text { Takeuchi (1997) }\end{array}$ \\
\hline $\begin{array}{l}\text { A gestão do conhecimento é um } \\
\text { processo de coleta, distribuição } \\
\text { e utilização eficiente dos } \\
\text { recursos de conhecimento em } \\
\text { toda a organização. }\end{array}$ & $\begin{array}{l}\text { Davenport et } \\
\text { al. (1998) }\end{array}$ \\
\hline $\begin{array}{l}\text { Um processo de criação, } \\
\text { validação, apresentação, } \\
\text { distribuição e aplicação que } \\
\text { permitem a uma organização } \\
\text { aprender, refletir, desaprender e } \\
\text { reaprender, sendo estas cinco } \\
\text { fases consideradas essenciais } \\
\text { para construção, manutenção e } \\
\text { reabastecimento das } \\
\text { competências principais. }\end{array}$ & Bhatt (2001) \\
\hline $\begin{array}{l}\text { Gestão do conhecimento refere- } \\
\text { se ao gerenciamento de } \\
\text { processos que governam a } \\
\text { criação, disseminação e } \\
\text { utilização do conhecimento por } \\
\text { meio da fusão de tecnologias, } \\
\text { estruturas organizacionais e } \\
\text { pessoas } \\
\text { para criar um aprendizado mais } \\
\text { efetivo, resolver problemas e } \\
\text { tomar decisão em uma } \\
\text { organização. }\end{array}$ & $\begin{array}{l}\text { Na Ubon e Kimble } \\
\qquad(2002)\end{array}$ \\
\hline $\begin{array}{l}\text { Gestão do Conhecimento é um } \\
\text { processo que facilita a partilha } \\
\text { de conhecimentos e estabelece } \\
\text { aprendizagem como um }\end{array}$ & $\begin{array}{l}\text { Lopez et al. } \\
\text { (2004) }\end{array}$ \\
\hline
\end{tabular}

1 O quadro não abrange todos os conceitos existentes na literatura. No entanto, fornece um entendimento abrangente sobre como são tratados os conceitos do termo gestão do conhecimento. processo contínuo dentro de uma organização.

Quadro 1: Conceitos de gestão do conhecimento

Fonte: Elaborado pelos autores

Percebe-se pelos conceitos apresentados que a gestão do conhecimento está ligada a maneira como as organizações criam, armazenam, disseminam e usam o conhecimento. Também define os padrões de interação entre as pessoas, as tecnologias e a estrutura organizacional no processo de criação do conhecimento e utilização deste para a resolução dos problemas organizacionais, bem como para a tomada de decisão.

A gestão do conhecimento tem como pressuposto que o recurso mais valoroso das organizações reside nas pessoas e é seu conhecimento. Portanto, à medida que uma organização tem sucesso, irá depender, entre outras coisas, em como efetivamente o seu pessoal poderá criar novo conhecimento, compartilhá-lo com a organização e usá-lo para melhorar o resultado organizacional (SERVIN, 2005).

A gestão do conhecimento envolve a aplicação do conhecimento de toda a força de trabalho para alcançar objetivos organizacionais específicos. Isso demanda que as pessoas tenham o conhecimento disponível onde e quando precisarem - o conhecimento certo, no lugar certo, no tempo certo. Para tanto, a gestão do 
conhecimento se preocupa com a facilitação de processos pelos quais o conhecimento é criado, compartilhado e usado nas organizações.

Uma abordagem popular e muito utilizada é pensar na gestão do conhecimento em termos de três componentes, quais sejam: pessoas, processos e tecnologia. Em relação às pessoas, a cultura voltada para a gestão do conhecimento é o mais importante e o maior desafio. Deve estar voltada para o aprendizado contínuo, de forma a motivar e recompensar as pessoas por criar, compartilhar e usar o conhecimento. Já os processos, devem acompanhar a cultura da organização, pois caso a mesma promova o compartilhamento do conhecimento, mudanças nos processos internos e até na estrutura organizacional podem ser necessárias. A tecnologia se apresenta como crucial, mas não é a solução, pois é de fundamental importância que a tecnologia usada nas organizações encaixe pessoas e processos da organização, caso contrário, ficará inutilizada (SERVIN, 2005).

\section{Liderança autêntica e a gestão do conhecimento}

Nas organizações intensivas em conhecimento, a liderança precisa absorver sua responsabilidade em relação à forma como ocorre à cooperação, o intercâmbio de conhecimentos, a delegação de responsabilidades e competências intra e interorganizacionais. Em suma, exerce influência em toda a dinâmica rede da aprendizagem, bem como no compartilhamento do conhecimento organizacional (BARTLETT: GHOSHAL, 2002). É importante que a alta administração estabeleça os pré-requisitos para a gestão do conhecimento pautada nas macrovisões organizacionais (NONAKA; TAKEUCHI, 1997). A partir deste prisma, tem-se que a liderança enquanto processo deve servir como fonte de inspiração e motivação, propondo e aprovando novas ideias, valorizando as diferenças individuais (HERRERA, 2008). Com uma comunicação eficaz, explicando os objetivos da gestão do conhecimento e os caminhos a serem seguidos, a liderança pode atuar como um agente de mudança e transformação corporativa (DEBOWSKI, 2006 apud SING, 2008).

Compete ao líder agir como um verdadeiro "arquiteto do saber", capacitando membros da organização por meio do desenvolvimento de uma visão compartilhada, fornecendo recursos, delegando autoridade e celebrando o sucesso (HITT, 1995 apud CRAWFORD, 2005). Neste cenário, o líder desempenha inúmeros papéis, como o de professor, mentor, guia ou facilitador no complexo e dinâmico processo de compartilhamento 
do conhecimento, estabelecendo o necessário alinhamento entre a realidade vivida e a visão de mundo estabelecida, a qual deve ser compartilhada por todos (SENGE,1997). Tais desafios requerem que os novos líderes atuem e exerçam influência em áreas específicas tais como: maximização da recepção de mensagens, criação e compartilhamento de conhecimento, promovendo a autoconsciência e autodesenvolvimento, elevando a autoconfiança e, permitindo a navegação por meio de um ambiente em constante transformação (WALDERSEE, 1997 apud CRAWFORD 2005).

A liderança autêntica pode contribuir na formulação, implementação e sustentação da gestão do conhecimento nas organizações, à medida que influência as pessoas, na promoção de relações transparentes e autênticas auferindo simultaneamente consistência e precisão às iniciativas de gestão do conhecimento. Por meio do processo de liderança é possível não só dar o exemplo (compartilhar conhecimentos), mas acima de tudo auxiliar na construção de compromissos mútuos (SING, 2008; HERRERA, 2008), para que a gestão do conhecimento seja algo perene, permeando todos os níveis da organização (SING, 2008).

Neste contexto, acredita-se que o exercício da liderança nas organizações do conhecimento prescinde da autenticidade e da participação de todos (AVOLIO; GARDNER, 2005). A liderança do tipo autêntica é capaz de refletir, criticar e questionar continuamente a maneira como a organização atua e pensa, e assim, pode se comprometer com a inovação dos produtos, processo e serviços a partir do intercâmbio e uso produtivo do conhecimento gerado na organização.

A liderança autêntica na gestão do conhecimento pode atuar como um facilitador e promotor de processos e relações, num cenário coletivo e incerto, o que pressupõe um empoderamento dos membros do grupo. Isso caracteriza um estilo de liderança participativa e a autogestão alinhada com as novas demandas dos profissionais, organizações e de uma sociedade baseada em conhecimento (FREITAS, 2000). Essas características da liderança autêntica podem colaborar com o compartilhamento de conhecimento, experiências e informações.

O nível de compartilhamento está diretamente relacionado com o grau de confiança, reconhecimento da organização e satisfação de seus atores (SENGE, 1997). A satisfação pessoal deriva da conquista organizacional, admiração e reconhecimento (FREITAS, 2000). Neste contexto, os líderes do conhecimento tem a importante função compreender as pessoas, os processos e os sistemas que compõem a 
organização, bem como seus princípios de negócio (DEBOWSKI, 2006 apud SING, 2008). O líder precisa reconhecer, orientar e motivar para que todos compartilhem o conhecimento para que os objetivos e expectativas sejam alcançadas, tanto no âmbito individual quanto organizacional. Assim, a satisfação e a confiança realimenta o ciclo da gestão do conhecimento com sucesso (BRYANT, 2003 apud CRAWFORD 2005).

\section{Considerações finais}

A teoria da liderança autêntica começou a ser desenvolvida recentemente. Surgiu da necessidade percebida na sociedade e, principalmente, nas organizações, de líderes que sejam conduzidos por fortes valores éticos e morais. Está amparada nos pressupostos da autenticidade, ou seja, além do componente ético/moral, o líder autêntico tem consciência dos pontos fortes e fracos, emoções e valores, processa informações de forma imparcial, age de acordo com seu eu verdadeiro, e desenvolve relações autênticas.

Observa-se que a liderança autêntica tem muito a caminhar para que a teoria se consolide. Muitos estudos envolvendo a temática são desenvolvidos em países como Estados Unidos da América e Inglaterra, ao contrário do que acontece no Brasil. Em geral, esses estudos são teóricos e buscam construir modelos de liderança autêntica. Focam nos fatores que compõem tal teoria, nos componentes de seu desenvolvimento, bem como a relacionam com outros fatores em busca de efetividade no alcance dos objetivos organizacionais.

Dentre os estudos sobre a teoria da liderança autêntica, alguns pontos merecem destaque: a liderança autêntica tem um forte caráter ético/moral; a autenticidade é um fator fundamental no contexto da liderança autêntica; líderes autênticos têm autoconhecimento; líderes autênticos agem de acordo com o seu eu verdadeiro, alinhando suas ações e comportamento aos seus valores; líderes autênticos desenvolvem relações transparentes; líderes autênticos fomentam o desenvolvimento de seus seguidores; o desenvolvimento de seguidores autênticos é inerente ao processo de liderança autêntica.

As características da liderança autêntica podem contribuir com a construção de uma cultura organizacional baseada em valores éticos/morais, um clima organizacional positivo e um desempenho organizacional, pautado não somente em fatores financeiros, mas também em humanos e sociais. Diante desse cenário, a liderança autêntica pode contribuir com a gestão do conhecimento. Visto que a ética e autenticidade nas 
relações podem favorecer a criação e compartilhamento do conhecimento, contribuindo com o desempenho organizacional.

\section{Referências}

AVOLIO, Bruce J. GARDNER, William L. Authentic leadership development: Getting to the root of positive forms of leadership. The Leadership Quarterly 16 (2005) 315-338.

AVOLIO, Bruce. J. et al. Unlocking the mask: A look at the process by which authentic leaders impact follower attitudes and behaviors. The Leadership Quarterly, 15, (2004) 801-823.

AVOLIO, Bruce J.; WALUMBWA, Fred O.; WEBER, Todd J. Leadership: Current Theories,

Research, and Future Directions. Annual

Review of Psychology. 2009. 60:421-49.

BARTLETT, Christopher A.; GHOSHAL, S. Human Resource management and Industrial Relations. Sloan Management Review, 43 (2) p. 34-41. 2002.

BASS, Bernard. Concepts of Leadership. In: VECCHIO, Robert P. Leadership: Understanding the Dynamics of Power and Influence in Organizations. 2 ed. Notre Dame: University of Notre Dame Press, 2007.

\section{Bass e Stogdill's}

Handbook of Leadership: Theory, Research, and Managerial Applications, New York: The Free Press, 3 ed., 1990.

BHATT, Ganesh D., Knowledge management in organizations: examining the interaction between technologies, techniques, and people. Journal of
Knowledge Management, 5 (1), 68-75, 2001.

BROWN, Michael E.; TREVIÑO, Linda K. Ethical leadership: A review and future directions. The Leadership Quarterly 17 (2006) 595-616.

CASTELLS, M.. A era da informação: economia, sociedade e cultura. In: A Sociedade em rede, v. 1. São Paulo: Paz e Terra, 1999.

COOPER, Cecily D.; SCANDURA, Terri A.; SCHRIESHEIM, Chester. A. Looking forward but learning from our past: Potential challenges to developing authentic leadership theory and authentic leaders. The Leadership Quarterly. 16 (2005) 475-493.

CRAWFORD, Chris B. Effects of transformational leadership and organizational position on knowledge management. Journal of Knowledge Management, v. 9 n. 6, 2005.

DAVENPORT, Thomas H.; DE LONG, Davi W.; BEERS, Michael C. Successful knowledge management projects. Sloan management review, vol. 39 no. 2, pp. 43-57, 1998.

DRUCKER, Peter. Sociedade PósCapitalista. 3. ed. São Paulo: Pioneira, 1993.

GARDNER, William L. et al. Can you see the real me? A self-based model of authentic leader and follower development. The Leadership Quarterly, 16 (2005) 343-372.

FREITAS, M. E. Cultura organizacional: identidade, sedução e carisma. Rio de Janeiro: FGV, 2000.

HERRERA, Cristhian Guillermo Naranjo. El liderazgo en la gestión del conocimento. Disponível em: 
http://www.umanizales.edu.co/programs/ps icologia/Perspectivas.pdf $>$. Acesso em: 25 mai 2010.

LOPEZ, S. P.; PEON, J. M. M.; ORDAS, C. J. V. Managing knowledge: the link between culture and Organizational learning. Journal of knowledge management, vol. 8 no. 6, pp. 93-104, 2004.

NA UBON, A.; KIMBLE, C. Knowledge management in online distance education. In: Proceedings of the $3 \mathrm{rd}$ International Conference Networked learning 2002, University of Sheffield, UK, March 2002, p. 465-473.

NONAKA, Ikujiro; KONNO, Noboru, The concept of "Ba": Building a foundation for knowledge creation. California Management Review, 40(3), 40-54, 1998.

NONAKA, Ikujiro; TAKEUCHI, Hirotaka. Criação de conhecimento na empresa: como as empresas japonesas geram a dinamica da inovação. Rio de Janeiro: Campus, 1997.

NORTHOUSE, Peter Guy. Leadership: Theory and practices. Sage Publications, Inc.:3 ed. 2004

OCDE. Manual de Oslo: proposta de diretrizes para coleta e interpretação de dados sobre inovação tecnológica, 1997. Tradução: Finep, 2004. Disponível em: < www.finep.gov.br/imprensa/sala_imprensa /manual_de_oslo.pdf $>$. Acesso em: 10 Mai. 2009.

SENGE, Peter. O novo trabalho do líder: Construindo organizações que aprendem. In: STARKEY, K. (Org). Como as Organizações Aprendem. São Paulo: Futura, 1997.

SERVIN, Géraud. ABC of Knowledge Management. NHS National Library for Health, july 2005.

SHAMIR, Boas; EILAM, Galite. What's your story?: A life-stories approach to authentic leadership development. The Leadership Quarterly. 16 (2005) 395417.

SPARROWE, Raymond T. Authentic leadership and the narrative self. The Leadership Quarterly. 16 (2005) 419439.

WALUMBWA, Fred O. Authentic Leadership: Development and Validation of a Theory-Based Measure? Journal of Management. 2008.

YUKL, Gary. Liderazgo en las organizaciones. 6 ed. Madrid: Pearson/Prentice Hall, 2008. 